\title{
IMPACTO TERRITORIAL DO TERREMOTO AO SETOR TURÍSTICO DE CANTÓN BOLÍVAR, EQUADOR
}

\author{
IMPACTO TERRITORIAL DEL TERREMOTO AL SECTOR \\ TURÍSTICO DEL CANTÓN BOLÍVAR, ECUADOR
}

\section{TERRITORIAL IMPACT OF THE EARTHQUAKE ON THE TOURIST SECTOR OF CANTÓN BOLÍVAR, ECUADOR}

Licença CC BY:

Artigo distribuído

sob os termos Creative Commons, permite uso e distribuição irrestrita em qualquer meio desde que o autor credite a fonte original.

NELSON GARCIA REINOSO

Máster en Gestión Turística por la Universidad Central "Marta Abreu" de las Villas.

Profesor de la carrera de Turismo de la Escuela Superior Politécnica

Agropecuaria de Manabí "Manuel Félix López" - ESPAM MFL - Cantón

Bolívar, Manabí, Ecuador.

nelsongreinoso@gmail.com

http://orcid.org/0000-0003-0972-3347

YAMIL DOUMET CHILÁN

Licenciado en Turismo por la UNIRONDON Brasil.

Profesor Titular de Turismo de la Escuela Superior Politécnica

Agropecuaria de Manabí "Manuel Félix López" - ESPAM MFL - Cantón

Bolívar, Manabí - Ecuador.

doumetour@hotmail.com

http://orcid.org/0000-0003-4295-5270

\section{RODNEY ALFONSO ALFONSO}

Máster en Gestión Turística por la Universidad Central "Marta Abreu" de las Villas.

Profesor de la carrera de Turismo de la Escuela Superior Politécnica Agropecuaria de Manabí "Manuel Félix López" - ESPAM MFL - Cantón

Bolívar, Manabí - Ecuador.

rodney7alfonso@gmail.com

http://orcid.org/0000-0002-4260-8992

DATA DE SUBMISSÃO: 04/11/2017 - DATA DE ACEITE: 17/08/2018

RESUMO: No dia 16 de abril de 2016, um terremoto de 7,8 graus na escala Richter sacudiu a costa noroeste do Equador. O evento causou grandes perdas para o sector do turismo. O custo total da reconstrução é estimado em USD 3344 milhões, o setor da hotelaria, alimentação e lazer na província de Manabí foi destruído em $80 \%$. Nesse contexto, o artigo tem como objetivo avaliar os impactos causados pelo terremoto e identificar estratégias de reativação do turismo que garantam um replanejamento do turismo no cantão de Bolívar. A metodologia adotada em sua primeira fase propõe um diagnóstico do turismo situacional para avaliar os impactos negativos causados pelo terremoto, avaliação de serviços, infraestrutura, superestrutura e acessibilidade a recursos naturais e culturais. Em sua segunda fase, propõe-se realizar um planejamento 
turístico. A ferramenta SWOT é utilizada para o estudo. Com base nos principais resultados da pesquisa, são identificadas cinco estratégias voltadas para a restauração da infraestrutura; estabelecimento de um sistema adequado de governança do turismo; concepção de programas de sensibilização no cuidado e conservação do patrimônio natural e cultural; fortalecer a promoção e marketing; administrar recursos financeiros nacionais e internacionais não reembolsáveis para reativação.

PALAVRAS-CHAVE: territorialidade, desenvolvimento do turismo, estratégias de reorientação.

RESUMEN: El 16 de abril de 2016 un terremoto de magnitud 7,8 grados en la escala de Richter sacude la costa noroeste de Ecuador, el evento provocó grandes pérdidas al sector turístico, el costo total de la reconstrucción se estima en 3344 MM USD, el sector hotelero, alimenticio y de diversión de la provincia de Manabí se destruyó en 80\%. En este contexto, el artículo tiene como objetivo evaluar los impactos causados por el terremoto e identificar estrategias de reactivación turística que garanticen una replanificación del turismo en el cantón Bolívar. La metodología adoptada en su primera fase propone realizar un diagnóstico turístico situacional para valorar los impactos negativos causados por el terremoto; evaluando los servicios, infraestructura, superestructura y accesibilidad a los recursos naturales y culturales. En su segunda fase plantea realizar una planificación turística, se utiliza la herramienta FODA. Con base a los principales resultados de la investigación se identifican cinco estrategias encaminadas al restablecimiento de la infraestructura; establecimiento de un sistema adecuado de gobernanza turística; diseño de programas de sensibilización y concienciación en el cuidado y la conservación del patrimonio natural y cultural; fortalecer la promoción, comercialización; y gestionar recursos financieros nacionales e internacionales no reembolsable para la reactivación.

PALABRAS CLAVE: territorialidad, desarrollo turístico, estrategias de reorientación.

ABSTRACT: On April 16, 2016 an earthquake of magnitude 7.8 on the Richter scale shook the northwest coast of Ecuador. The total cost of reconstruction following this event is estimated at 3344 million USD, and it caused significant losses for the tourism sector. The hotel, food and entertainment sectors in the province of Manabí were $80 \%$ destroyed. This article aims to investigate the impacts caused by the earthquake and to identify tourism reactivation strategies that will guarantee a replanning of tourism in the canton of Bolívar. The methodology adopted in the first phase proposes a situational diagnosis of tourism to assess the negative impacts caused by the earthquake; evaluation of the services, infrastructure, superstructure and accessibility to natural and cultural resources. In its second phase, a tourism planning is proposed, using SWOT analysis. Based on the main results of the research, five strategies aimed at restoring the tourism infrastructure are identified; establishment of an adequate system of tourism governance; design of programs to raise awareness and promote care and preservation of the natural and cultural heritage; strengthening promotion and marketing; and management of nonreimbursable national and international financial resources for reactivation.

Keywords: territoriality, tourism development, reorientation strategies.

\section{INTRODUCCIÓN}

En Ecuador, el turismo se ha transformado en los últimos tiempos en una de las actividades económicas más importantes, debido a la entrada de divisa y a la diversificación del ingreso que esta genera en los destinos receptivos. Según Reyes et al. (2012) para Ecuador el turismo constituye uno de los rubros de generación de divisas más significativos, presentándose como un sector estratégico para el desarrollo del país, puesto que es una actividad generadora de empleo y de redistribución de la riqueza, integradora y complementaria con múltiples actividades para la superación de la pobreza y el desarrollo sostenible del país. 
El Ecuador está dentro de los cinco países más afectados de Latinoamérica, de acuerdo con estadísticas de Smithtravel Search, una compañía que mide los índices de ocupación y tarifa promedio de cada mercado. Comparativamente con países cercanos como Colombia, Chile y Perú, la devaluación de sus monedas vuelve automáticamente más caros a Ecuador y eso afecta al negocio de congresos, incentivos y convenciones. La ocupación hotelera de Ecuador en 2015 fue de 65,6\% y hasta abril de 2016 bajó a 57,2\%, lo que significa que un poco más de cuatro de cada diez camas existentes están vacías. Entre los motivos para esta caída se incluyen la apreciación del dólar que convierte al país en un destino más costoso frente a países vecinos, y la tendencia de alojamiento alternativo en casas y departamentos privados.

El sábado 16 de abril de 2016 a las 18:58 hora local, se registró un terremoto de magnitud 7,8 (Mw) en la costa noroeste de Ecuador. El sismo se prolongó cerca de 75 segundos, con una fase más intensa de movimiento de aproximadamente 15 segundos. De acuerdo con la Escala Macrosísmica Europea, el terremoto fue perceptible en la mayoría de zonas del oeste del país. Durante los días subsiguientes, se registraron seis réplicas de magnitud entre 6,0 y 6,7 .

Los principales resultados encontrados en la población afectada primaria dan cuenta de 661 fallecidos en el terremoto del 16 de abril 663 considerando las réplicas del 18 de mayo), 12 desaparecidos, 4859 atenciones a heridos y 80 mil desplazados por pérdida o daño de sus viviendas. Entre las principales afectaciones secundarias se registran 120 mil estudiantes con limitado acceso al sistema educativo, 593 mil personas con limitado acceso a los servicios de salud, 500 mil personas con inseguridad alimentaria, 350 mil personas con acceso restringido a agua en los primeros días luego del terremoto, 170 mil personas con afectaciones en sus medios de vida y 200 mil personas con afectaciones psicológicas. (Comité para Reconstrucción y Reactivación Productiva, 2016)

La caída del turismo a nivel de país en el año 2016 posterremoto es de entre 20 y $25 \%$ en lo que a hospedaje se refiere que es lo que determina de mejor forma la relación. Sin embargo, a nivel país hay zonas donde las caídas son de hasta 40\%, como Manabí y otras provincias de la Costa. En esta situación se ha visto afectado el empleo en el sector turístico, se ha determinado que al menos entre 20 y 25\% del personal ha sido retirado. Más de 3.566 locales (emprendimientos) registrados se alistan para recibir cada fin de semana a viajeros nacionales e internacionales, motivados por el turismo de sol y playa. Desde el 16 de abril, las estadísticas variaron drásticamente (MINTUR, 2016).

La provincia costera de Manabí no encabezaba la lista del turismo interno. De hecho, se ubica en el quinto puesto de las más visitadas, sin embargo, recibía alrededor de 600.000 visitantes al año. Esa cifra representa aproximadamente $30 \%$ de los casi dos millones de turistas que recibe Ecuador, según el Ministerio de Turismo (2016). La Dirección Provincial de Turismo de Manabí revela que un visitante de paso genera entre \$15 y \$30 dólares estadounidense por un día de visita en las localidades, si no se hospeda. Si permanece más de un día, inyecta entre \$100 y \$120 dólares a la economía, incluyendo servicios hoteleros.

El costo total de la reconstrucción se estima en 3344 MM USD. De este monto, el $75,1 \%$ corresponde a la reconstrucción, $18,3 \%$ a flujos perdidos y $6,6 \%$ a la respuesta inmediata. El 40,9\% del monto total corresponde al sector social, 25,8\% a infraestructura, 
$30,9 \%$ al sector productivo y el 2,4\% restante a otros sectores que son transversales a la economía. Finalmente, el 67,4\% del monto total será financiado por el sector público y el 32,6\% por el sector privado. (Comité para Reconstrucción y Reactivación Productiva, 2016)

El costo de la reconstrucción del sector social asciende a 1369 MM USD, que representa el 40,9\% del monto total de reconstrucción del país. De este monto, el 85,3\% corresponde a la reconstrucción, 9,5\% a costos adicionales y 5,1\% a flujos perdidos. Asimismo, el 47,7\% del costo corresponde a vivienda, 31,8\% a educación, 17,6\% a salud y el 2,9\% restante a patrimonio y cultura. (Secretaría General de Riesgos de Ecuador, 2016).

En el subsector patrimonio y cultura se estimó un costo total de reconstrucción de 40 MM USD (2,9\% del sector social) que incluye la reconstrucción de activos y los flujos perdidos. Las afectaciones en activos en el subsector cultura se concentró en Manabí que cuenta con 6180 bienes patrimoniales inventariados, de los cuales el 45\% tiene afectaciones medias y altas, el $80 \%$ de los contenedores culturales que albergan el patrimonio mueble tiene afectaciones importantes y el $40 \%$ del patrimonio arqueológico tuvo afectaciones mediana y baja, con mayores riesgos vinculados a su conservación debido al daño de los contenedores donde se encuentran. En el caso del patrimonio cultural inmaterial, el 40\% del patrimonio inventariado en la región tuvo afectaciones. El 61,8\% de la afectación se dio en patrimonio inmueble y sitios arqueológicos, 19,7\% en infraestructura y equipamientos que perdió la industria cultural, 15,2\% en repositorios y 3,3\% en patrimonio inmaterial. (Comité para Reconstrucción y Reactivación Productiva, 2016)

En el subsector turismo se estimó un costo total de reconstrucción de 97 MM USD (9,4\% del sector productivo), monto que incluye el costo de la respuesta inmediata al evento, la reconstrucción de activos y los flujos perdidos. El subsector tuvo importantes afectaciones en los activos: se perdió el 22,2\% del total de activos registrados en el año 2014 en la zona afectada. El 98,6\% de esas afectaciones se concentra en empresas pequeñas. Los activos que resultaron mayormente afectados corresponden a edificios e instalaciones pertenecientes principalmente a pequeñas empresas, microempresas y personas naturales. La reconstrucción de activos en el subsector de turismo asciende a 76,8 MM USD. Las pérdidas para el subsector turismo se estiman en 19,5 MM USD que representan cerca del 13,3\% de las ventas anuales previas al terremoto. (Secretaría General de Riesgos de Ecuador, 2016).

Tras el terremoto el Gobierno nacional estableció incentivos y medidas exclusivas para el sector turístico. Entre estas se contempla la exoneración del impuesto a la renta para nuevas inversiones productivas que se podrá extender hasta por diez años, acceso a créditos financieros para proyectos turísticos o emprendimientos de oferta turística en las zonas afectadas por el terremoto y la exoneración del pago del impuesto a la salida de divisas y los aranceles destinados a procesos productivos turísticos o a la prestación de este tipo de servicios dentro de las zonas afectadas.

El sistema turístico en la provincia de Manabí fue afectado considerablemente por el terremoto del 16 de abril del 2016, Garcia et al (2016) considera que constituye un objetivo de estudio y de diagnóstico en la actualidad. Dentro del territorio del cantón Bolívar, destaca Garcia et al., (2017) se observan comunidades que poseen una amplia gama de atractivos y recursos turísticos naturales y culturales; los pobladores mantienen tradiciones propias de la zona. Pero la actividad turística, no ha mostrado avances en su infraestructura y planificación 
estratégica, y no existen planes de acción específicos en ejecución, que promuevan la participación de las instituciones públicas y privadas del territorio.

Garcia et al (2016) considera que la actividad turística en el cantón Bolívar post terremoto del 16 de abril del 2016, debe replanificarse, así lo exige la nueva realidad, se hace necesario diagnosticar los recursos turísticos, evaluar los daños, identificar los problemas y sus causas que motivan el estancamiento en la gestión turística, conocer las necesidades y exigencias de los prestadores de servicios turísticos afectados por el terremoto, rediseñar nuevos productos dirigidos a motivar la demanda e implementar estrategias que motiven la reactivación de la actividad turística.

Todos estos problemas que aquejan al sector turístico llevan a que no se proyecte una pronta recuperación. Para comenzar a reactivarlo se requiere un trabajo conjunto entre el sector privado y el sector público. Estas problemáticas justifican la investigación validando la necesidad de identificar estrategias de reactivación turísticas encaminadas al desarrollo del turismo del cantón Bolívar.

\section{FUNDAMENTACIÓN TEÓRICA DESARROLLO SOSTENIBLE DEL TURISMO EN ECUADOR.}

Para Domareski et al., (2015) el desarrollo del turismo está directamente relacionado con la comunidad $y$, si se gestiona bien, el turismo puede considerarse una importante herramienta para la mejora social. Construir una estrategia de desarrollo sostenible para Tomás Carpí (2008) es el cauce de las sociedades locales para desplegar las capacidades que impulsen su modernización, competitividad, creatividad, profundización de la democracia, educación cívica y su sentido de la solidaridad; todo lo cual contribuye a garantizar el bienestar de las generaciones presentes y futuras.

El Gobierno de Ecuador, desde una perspectiva de inclusión económica y social, según Funes et al, (2015) busca promover un desarrollo territorial equilibrado e integrado, orientado a reducir la pobreza y diferencias a las que han estado sometidos tradicionalmente determinadas comunidades. En este contexto el Gobierno Nacional de Ecuador por intermedio de la Secretaria Nacional de Planificación y Desarrollo (SENPLADES, 2013) con el Plan Nacional del Buen Vivir, apunta a la consolidación de un nuevo modelo, en el que las políticas públicas para la igualdad sean transversales a la acción de las entidades estatales.

El desarrollo turístico territorial ha de estar basado sobre el diseño de productos y servicios específicos, procedentes del lugar que promuevan el crecimiento de la actividad económica y/o diversificación de la estructura productiva del territorio, es un proceso complejo y necesita la intervención de muchos actores que impulsen el crecimiento económico, políticas públicas fomentando valores que permitan a la población identificarse con su territorio donde se integren al protagonismo que asumen los actores en cuanto al poder de decisión y gestión de sus propios recursos, y donde resultan fundamentales las capacidades locales, tales como el conocimiento, la creación, la innovación, el emprendimiento, las formas de organización, articulación, diálogo, consenso y participación, así como los vínculos basados en la confianza. 


\section{GOBERNANZA, ESTRATEGIA TURÍSTICA EN LAS POLÍTICAS PÚBLICAS}

El concepto gobernanza según Moscoso (2013) hace referencia a la creación de redes de cooperación y coordinación entre los actores directa e indirectamente implicados en la cadena de valor del turismo, que se caracterizan por tener sus propias reglas y normas. Es un proceso continuo por el cual es posible acomodar intereses conflictivos o diferentes y realizar acciones cooperativas. Según Furtado da Silva et al, (2012) la gobernanza se refiere no sólo a las instituciones y regímenes formales autorizados a imponer obediencia, sino también a los acuerdos informales que atienden los intereses de las personas e instituciones.

La gobernanza turística podría definirse como una práctica de gobierno que se puede medir, que tiene como objetivo dirigir efectivamente el turismo en los diferentes niveles de gobierno en la articulación entre la acción pública, privada y colectiva donde la integración, coordinación y colaboración en el desarrollo de estas redes de cooperación permitirán al territorio, alcanzar los objetivos de interés colectivo que comparten redes de actores involucrados en el sector turístico permitiendo alcanzar la competitividad por medio de la formulación de políticas y de una planificación estratégica integral, donde se alcancen acuerdos basados en el reconocimiento de las interdependencias y responsabilidades compartidas.

El desarrollo de un municipio turístico considera Wallingre (2014) necesita de la participación de numerosos actores, cada uno de ellos buscará atender a los requerimientos y las expectativas concretas, muchas veces sectoriales, orientadas a responder a la demanda, y a las necesidades de los visitantes, las cuales deben sostenerse en condiciones que aseguren su sustentabilidad. Se requiere una clara identificación de los actores que asumirán el compromiso de liderar las acciones de desarrollo.

La política pública se entiende según Scarpeta et al., (2017) como las acciones del gobierno para la gestión de temas específicos, en este caso, las acciones del gobierno para desarrollar el uso público en las Unidades de Conservación. La gestión pública en el contexto actual tiene como uno de sus objetivos para Fontenele et al., (2015) emprender principios orientadores y normas regulatorias para gestionar las diferentes esferas estatales conduciendo a acciones asertivas y coherentes con las demandas, particularidades de aquel determinado territorio.

Para Perelló (2015), las estrategias políticas deben reflejar la voluntad pública y estar sujeta a los cambios que ésta determine. Como en cualquier lugar Cabral (2016) considera que la política pública tiene un papel importante en la gestión del turismo local, principalmente en la mediación entre los turistas, la población local y el sector privado. Las políticas turísticas son una expresión de las políticas públicas sobre el territorio y en conformidad con su carácter sistémico se alcanzan aspectos económicos, sociales, ambientales y culturales, contribuyen al ordenamiento del territorio y en su economía, resultando un elemento primordial en la planificación turística. 


\section{EL TERRITORIO Y LA TERRITORIALIDAD EN LA PLANIFICACIÓN TURÍSTICA}

El territorio es un componente fundamental del sistema turístico según Wallingre (2014), en el que interactúan tanto los visitantes como los residentes, y el conglomerado de empresas y organismos del sector que llevarán adelante los procesos de desarrollo. Perelló (2015) plantea que la transformación productiva de un territorio de preferente uso turístico debe darse en un marco institucional determinado y éste tendría que ser pluralista y participativo en lo local.

La caracterización de un territorio se da a partir de muchos factores según Furtado da Silva et al. (2012) que, en consecuencia, acaban por delimitar las formas de ocupación y uso de un espacio geográfico dado. La principal característica en la relación turismoterritorio es lo que concierne a la producción y al consumo de territorios por el turismo, el principal objetivo de consumo del turismo es el espacio, el proceso de consumo de los espacios por parte del turismo se gestan los territorios turísticos, entender el territorio y la territorialidad implica además identificar y explicar las dinámicas, conocer el impacto de las actividades sobre los distintos grupos sociales y recursos naturales; el turismo, impacta de forma sistémica sobre el territorio.

La importancia que cada territorio tenga un diseño de modelo adaptable a cada región y a la calidad de los atractivos, para Cevallos (2015) tiene el fin de evaluar las potencialidades y debilidades y poder diseñar la mejor estrategia de promoción en beneficio de todos. En Ecuador, desde el año 2000, cita Wallingre (2014) se desarrolló un modelo de descentralización turística que busca consolidar la autoridad nacional como facilitadora del desarrollo sectorial, fortaleciendo el aspecto institucional de los municipios y los consejos provinciales para asunción de la gestión local del turismo.

El territorio es una categoría de análisis que expresa las características geográficas y las identidades culturales de las personas que habitan un lugar, la complejidad económica, social ambiental y política que configuran sus actores y mediaciones institucionales, es lo que se denomina territorialidad; que no es más que las relaciones económicas, políticas y socioculturales de un espacio geográfico determinado y que involucra actividades productivas y de servicios, dinámicas institucionales y construcción de identidad cultural.

La planificación turística debe promover para Carvalho, et al. (2011) la articulación integrada, el protagonismo comunitario, el fortalecimiento de la identidad, la valoración del lugar y su capitalización por medio del turismo. Según Toselli, et al. (2014) el planeamiento estratégico resulta de gran utilidad cuando se trata de abordar un proceso local de renovación económica, y a partir de su formulación es posible determinar objetivos en función de las oportunidades del entorno, coincidiendo con Velasco, (2016) al plantear que algunas de las metas más recurrentes son: Formular una estrategia de desarrollo del turismo en su conjunto o de algún subsector concreto a través de diversos instrumentos (Planes estratégicos, de ordenación turística, etc.).

Comprender al turismo como proceso de construcción social y su vinculación con el territorio, según Moscoso (2013) es entenderlo a partir de una lógica sistémica que busca lograr un equilibrio en términos de procesos dinámicos entre los distintos campos 
que conforman el lugar y los actores involucrados. Carvalho, et al. (2011) considera que el producto turístico abarca una serie de elementos necesarios para la atención de las expectativas de consumo de los visitantes (atractivos, accesibilidad, equipamientos y servicios) al apropiarse de los territorios, la actividad turística se convierte en uno de los principales agentes intervinientes de la dinámica de las relaciones sociales previamente establecidas, engendrando un proceso dialéctico de producción de nuevas territorialidades.

La planificación turística requiere de la definición de un modelo de desarrollo turístico mismo que exige el ejercicio consciente de la responsabilidad compartida de todos los actores involucrados, basados en valores que deben sustentarla como el diálogo, participación, consenso, compromiso, solidaridad donde se demuestre la capacidad de los actores territoriales y de la sociedad local para estructurarse y movilizarse en base a sus potencialidades y en la búsqueda de competitividad turística.

\section{METODOLOGÍA}

En la presente investigación se emplean métodos teóricos de análisis-síntesis, la inducción, la deducción, la abstracción, el histórico-lógico, la comparación y la revisión bibliográfica de la literatura relacionada con el tema de investigación, en la figura número 1, se muestra la metodología propuesta para la investigación.

Dentro de los métodos empíricos se utilizará la observación, las escalas valorativas, el trabajo en grupos, análisis documental, tormenta de ideas, matriz DAFO y encuesta estructurada como parte del procedimiento que permitirán medir los niveles de satisfacción de los actores turísticos. A demás de evaluar la demanda e identificar las preferencias y las motivaciones que la caracterizan.

Dentro de los métodos estadísticos son utilizados: los muestreos probabilísticos, se utilizará para el procesamiento estadístico de la información el programa estadístico informático SPSS (Statistical Package for the Social Sciences), se utilizó específicamente un muestreo probabilístico aleatorio simple. Para determinar el tamaño de la muestra se utiliza la metodología propuesta por González \& Conde (2011) pero siguiendo un criterio estadístico y asumiendo una población infinita, se fijó un nivel de confianza del 95\%, una proporción estimada de la población del $50 \%(p=0,5)$ y su complemento en igual proporción $(q=0,5)$ y se estimó un margen de error que varió desde $(0.06 \leq d \leq 0,1)$, según la siguiente ecuación:

$$
\mathrm{n}=\frac{Z_{a / 2}^{2} * p * q}{d^{2}}
$$




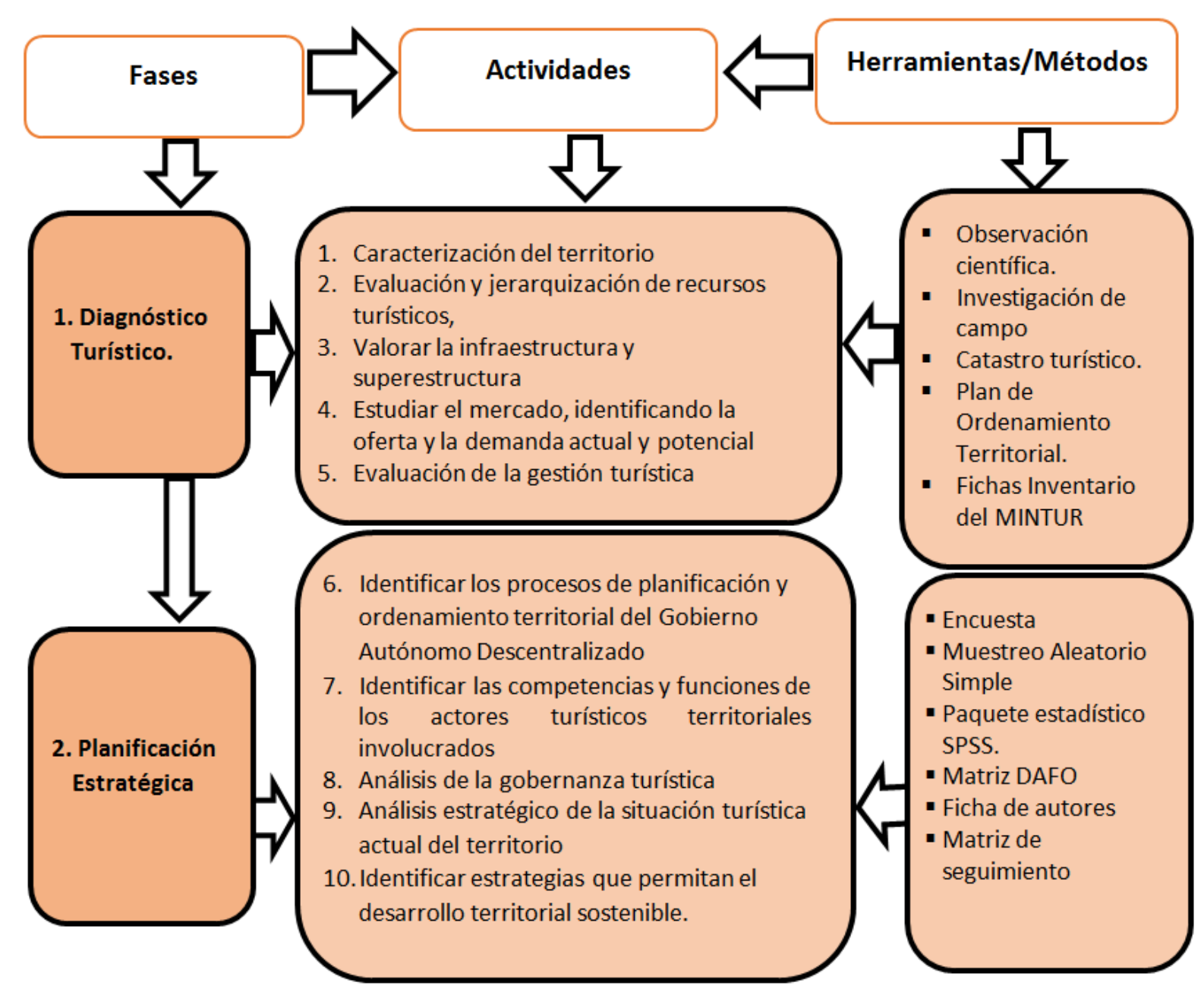

Figura 1. Metodología para evaluar el desarrollo turístico del territorio. Fuente: Elaborado por los autores

\section{FASE 1: DIAGNÓSTICO TURÍSTICO}

En el desarrollo de esta primera fase se diagnostica la situación actual del territorio delimitándose el área objeto de estudio, se recopilan datos generales y realiza una caracterización general: ambiental, social, cultural, económica y política del territorio, enfatizando en la actividad turística y contemplando una dimensión legal e institucional de las funciones que le competen al gobierno autónomo descentralizado del cantón Bolívar, que permitan la evaluación de la gestión turística, realizándose un análisis del catastro turístico, las normativas institucionales y el Plan de Desarrollo y Ordenamiento territorial del cantón.

Se realiza un inventario de recursos turísticos, su evaluación y jerarquización en función de conocer las potencialidades turísticas. Para dicho levantamiento de información se utiliza las fichas del MINTUR y el cuestionario propuesto por Ricaurte (2009), se le suma a este trabajo la experimentación y observación científica en terreno; otras de las actividades fundamentales en esta fase es el estudio de mercado, identificando la oferta y la demanda. Se efectúa además una evaluación de la infraestructura y superestructura y las sucesivas acciones que permitan visualizar sus potencialidades y debilidades, para ordenar y formar un sistema turístico sostenible. 


\section{FASE 2: PLANIFICACIÓN ESTRATÉGICA}

Analizar estratégicamente la situación turística actual del territorio, los procesos de planificación y ordenamiento territorial del Gobierno Autónomo Descentralizado del cantón Bolívar en relación al turismo, identificándose las competencias y funciones de los entes turísticos territoriales involucrados evaluándose la gobernanza turística y su integración entre los emprendedores, la comunidad y el gobierno en la gestión turística territorial que propicien como resultado tangible de la investigación la identificación de estrategias que permitan el desarrollo territorial sostenible.

\section{RESULTADOS EL DIAGNÓSTICO TURÍSTICO SITUACIONAL}

El cantón Bolívar está ubicado en el sector oriental de la provincia, su posición astronómica es $\mathrm{O}$ grados, 50 minutos y 39 segundos de latitud sur y 80 grados, 9 minutos y 33 segundos de longitud oeste. Limita al norte con el cantón Chone, al sur con Portoviejo y Junín al este con Pichincha y al oeste con Tosagua. El cantón presenta una topografía plana en la parte baja por los valles e irregular ondulada y quebrada en la parte alta y montañosa. La altitud es de $21 \mathrm{msnm}$ la parte baja y de $400 \mathrm{msnm}$ en la parte alta, tiene una superficie territorial de 537.8 Km2, y está dividida en una parroquia urbana: Calceta y dos rurales: Quiroga y Membrillo.

El cantón Bolívar presenta una característica eminentemente agrícola predominando productos como cacao, café y cítricos (ver cuadro 1). En condiciones de productos perenne y de mayor explotación. Aproximadamente en el cantón se producen alrededor de 13.000 hectáreas entre cacao y café. Existen alrededor de 520 fincas, de las cuales 360 corresponden al cultivo de cacao y 160 al cultivo de café, tomando en consideración un promedio general de 25 hectáreas por finqueros (Plan de Desarrollo y Ordenamiento Territorial del cantón Bolívar, 2016). A continuación, se presenta el cuadro 1, con los datos generales del cantón Bolívar de la provincia de Manabí.

\begin{tabular}{|c|c|}
\hline \multicolumn{2}{|r|}{ DATOS GENERALES DEL CANTÓN BOLÍVAR } \\
\hline $\begin{array}{l}\text { Ubicación } \\
\text { Astronómica }\end{array}$ & $\begin{array}{l}0 \text { grados, } 50 \text { minutos y } 39 \text { segundos de latitud sur y } 80 \text { grados, } 9 \text { minutos y } 33 \text { segundos } \\
\text { de longitud oeste. }\end{array}$ \\
\hline Límites & $\begin{array}{l}\text { Norte: Chone } \\
\text { Sur: Portoviejo y Junín } \\
\text { Este: Pichincha } \\
\text { Oeste: Tosagua }\end{array}$ \\
\hline Parroquias & Calceta (urbana), Quiroga y Membrillo (rurales) \\
\hline Superficie & $537.8 \mathrm{Km} 2$ \\
\hline Población & 40.735 Habitantes \\
\hline Hidrografía & Río Carrizal (Principal) \\
\hline Temperatura & 25,5o C (Temperatura media anual) \\
\hline Precipitación Anual & $1.300 \mathrm{~mm}$. \\
\hline Altitud & $21-400 \mathrm{msnm}$ \\
\hline
\end{tabular}

Fuente: Plan de Desarrollo y Ordenamiento Territorial del cantón Bolívar (2016), INEC (2010) 
El cantón Bolívar y su cabecera cantonal Calceta, es un vasto emporio de riqueza cultural, donde aún se mantienen vivas distintas expresiones de la cultura popular manabita, entre lo autóctono, la mezcla o combinación de raíces ancestrales y lo que significó la penetración y aculturación que produjo la invasión española. Con distintas temáticas encontramos bailes y danzas folklóricas en la que se expresan manifestaciones de costumbres y vivencias del ayer de los pueblos, acompañadas al sonido de una guitarra, acordeón, maraca o tambor.

Una tradición cultural que aún se encuentra vigente es la elaboración de exquisiteces gastronómicas, representadas en platos típicos como la tonga, caldo y seco de gallina criolla, la cuajada, entre otras. La celebración de sus fiestas patronales en honor a San Agustín los 27 y 28 de agosto de cada año, al igual que los 13 de octubre en los que se celebra su Cantonización, la elaboración de artesanías en barro y el Festival del Balsero en el cual rememoran la costumbre de los ancestros del cantón de utilizar sus balsas como medio de transporte ya sea de personas o de los productos que cosechaban en sus tierras.

\section{EVALUACIÓN Y JERARQUIZACIÓN DE LOS RECURSOS TURÍSTICOS}

Antes del terremoto, Manabí contaba con 3.566 establecimientos para el sector turístico. En esa cifra estaban hoteles, hostales, restaurantes y centros nocturnos. Tras el terremoto, más de 60\% de las estructuras colapsó, con mayores daños en Pedernales, Canoa, Portoviejo y Manta que eran los sitios con más visitantes en la provincia, luego de Puerto López (Comité para Reconstrucción y Reactivación Productiva, 2016).

La Secretaría Nacional de Planificación y Desarrollo (SENPLADES, 2016) contabilizó pérdidas por \$ 3.344 millones (M) en total, dinero que se requeriría para reconstruir las zonas afectadas que perjudican a más de 21.000 personas directa e indirectamente. Solo en Manabí, según datos del Anuario del Ministerio de Turismo, en establecimientos de alojamiento, alimentos y bebidas, transportación, operación, intermediación y centros de recreación, se empleaban a 8.199 personas de forma directa.

El cantón Bolívar posee elevados índices de potencialidad turística, los recursos naturales se ven reflejados en cascadas en la zona alta, el río Carrizal y sus balnearios, la represa Sixto Durán Ballén, paisajes acogedores, las manifestaciones culturales, una variada gastronomía típica, producción agropecuaria diversa, una de las zonas de mayor producción de cacao nacional de calidad, fiestas tradicionales, manifestaciones religiosas, fuerte arraigo a las expresiones orales y literarias, además entre su producción artesanal se aprecian sombreros y artículos de paja mocora, arte en zapán, instrumentos musicales y arte en caña guadua y mate.

El territorio posee un importante recurso hídrico la represa Sixto Durán Ballén conocida como "La Esperanza", que se abastece del río Carrizal, ubicada en la microregión centro-norte de Manabí, a 11 kilómetros de la ciudad de Calceta y que almacena 450 millones de $\mathrm{m} 3$ de agua. El canal del cauce del río Carrizal es uno de los principales recursos turísticos aprovechado por la población, en la actualidad la visita al embalse "La Esperanza", Las Lagunas de Bijagual, compuesta por 6 ciénagas de agua dulce y profundas posiblemente de origen volcánico, habitadas por tortugas, las cuevas de Membrillo lugar donde se han encontrado vestigios de asentamientos humanos, en las paredes se puede percibir grabados prehistóricos (ver tabla 1). 


\begin{tabular}{|c|c|c|c|}
\hline $\begin{array}{l}\text { NOMBRE DEL } \\
\text { ATRACTIVO }\end{array}$ & $\begin{array}{l}\text { CATEGORÍA/ } \\
\text { JERARQUIA }\end{array}$ & $\begin{array}{l}\text { ESTADO } \\
\text { ACTUAL }\end{array}$ & CARACTERÍSTICAS \\
\hline $\begin{array}{l}\text { Presa La } \\
\text { Esperanza } \\
\text { "Sixto Duran } \\
\text { Ballén" }\end{array}$ & $\begin{array}{l}\text { Sitio Natural } \\
\text { (II) }\end{array}$ & $\begin{array}{l}\text { Proceso de } \\
\text { deterioro }\end{array}$ & $\begin{array}{l}\text { El área de influencia de la presa es todo el cantón } \\
\text { Bolívar y varios cantones de Manabí en el ámbito } \\
\text { turístico se puede hablar de actividades como: paseo } \\
\text { en bote, avistamiento de aves, paisajismo, fotografía, } \\
\text { entre otras. }\end{array}$ \\
\hline $\begin{array}{l}\text { Balneario de } \\
\text { agua dulce } \\
\text { Platanales }\end{array}$ & $\begin{array}{l}\text { Sitio Natural } \\
\text { (II) }\end{array}$ & $\begin{array}{l}\text { Afectado } \\
\text { parcialmente, } \\
\text { daños en las } \\
\text { facilidades } \\
\text { turísticas. }\end{array}$ & $\begin{array}{l}\text { Este recurso está rodeado de un paisaje interesante } \\
\text { con una fuente natural que es el río Carrizal. }\end{array}$ \\
\hline $\begin{array}{l}\text { Balneario de } \\
\text { agua dulce Los } \\
\text { Almendros }\end{array}$ & $\begin{array}{l}\text { Sitio Natural } \\
\text { (II) }\end{array}$ & Conservado & $\begin{array}{l}\text { Su nombre se debe a que la principal característica } \\
\text { es la presencia de árboles de almendro, especie } \\
\text { predominante en el sitio. }\end{array}$ \\
\hline $\begin{array}{l}\text { Paraje Natural } \\
\text { y Cultural } \\
\text { Quinta Colina } \\
\text { del Sol }\end{array}$ & $\begin{array}{l}\text { Manifestación } \\
\text { Cultural/Sitio } \\
\text { Natural (II) }\end{array}$ & Conservado & $\begin{array}{l}\text { En este recurso natural se ve reflejada la preservación } \\
\text { de manifestaciones culturales del montubio manabita } \\
\text { y sus objetos de uso cotidiano. }\end{array}$ \\
\hline $\begin{array}{l}\text { Finca } \\
\text { Agroecológica } \\
\text { Sarita }\end{array}$ & $\begin{array}{l}\text { Manifestación } \\
\text { Cultural/Sitio } \\
\text { Natural (II) }\end{array}$ & Conservado & $\begin{array}{l}\text { Está ubicada en la Comunidad de Sarampión, este } \\
\text { sitio está conformado por } 2 \text { hectáreas de cultivos } \\
\text { (actividades agroforestales, cacao, permacultura). }\end{array}$ \\
\hline $\begin{array}{l}\text { Cascada } \\
\text { Primera Piedra }\end{array}$ & $\begin{array}{l}\text { Sitio Natural } \\
\text { (II) }\end{array}$ & $\begin{array}{l}\text { Proceso de } \\
\text { deterioro }\end{array}$ & $\begin{array}{l}\text { Es un conjunto de } 3 \text { cascadas, se encuentran ubicadas } \\
\text { a } 30 \mathrm{~km} \text { de Calceta, en la Comunidad Primer Piedra, } \\
\text { su caudal es permanente, y están rodeadas de } \\
\text { vegetación de bosque húmedo tropical. }\end{array}$ \\
\hline $\begin{array}{l}\text { Cascada de } \\
\text { Julián }\end{array}$ & $\begin{array}{l}\text { Sitio Natural } \\
\text { (II) }\end{array}$ & $\begin{array}{l}\text { Proceso de } \\
\text { deterioro }\end{array}$ & $\begin{array}{l}\text { Esta cascada cuenta con una caída de agua de } \\
\text { aproximadamente } 4 \text { metros de altura que forma, } \\
\text { finalmente, una pequeña piscina natural de agua } \\
\text { cristalina, su caudal es permanente y en la época de } \\
\text { invierno aumenta. }\end{array}$ \\
\hline $\begin{array}{l}\text { Cascada } \\
\text { Chapulí }\end{array}$ & $\begin{array}{l}\text { Sitio Natural } \\
\text { (II) }\end{array}$ & $\begin{array}{l}\text { Proceso de } \\
\text { deterioro }\end{array}$ & $\begin{array}{l}\text { Ubicada a } 26 \mathrm{Km} \text { de Calceta, tiene una altura de } 15 \\
\text { metros y } 3 \text { metros de ancho, su caudal es intermitente, } \\
\text { se puede disfrutar la temporada de Iluvia (Enero-Abril). }\end{array}$ \\
\hline $\begin{array}{l}\text { Bosque } \\
\text { Protegido } \\
\text { Primera Piedra }\end{array}$ & $\begin{array}{l}\text { Sitio Natural } \\
\text { (II) }\end{array}$ & Conservado & $\begin{array}{l}\text { El bosque protegido se ubica en la región norte de la } \\
\text { represa, a } 30 \mathrm{~km} \text { de Calceta en la comunidad Primera } \\
\text { Piedra. Pertenece a las áreas protegidas designadas al } \\
\text { Programa Socio Bosque. }\end{array}$ \\
\hline
\end{tabular}

Tabla 1. Inventario turístico de recursos naturales del cantón Bolívar

Fuente: Elaborado por los autores

Se percibe un uso inadecuado de cinco sitios naturales en proceso de deterioro donde se evidencian problemas tales como: Dispersos planes de manejo de cuencas hidrográficas, que no cuentan con apoyo institucional y apropiación de la población para su implementación; Contaminación de las fuentes y de los cursos de agua; Disminución de caudales de agua; Inequitativa distribución del recurso; y el Limitado acceso a la información y capacitación del sector rural sobre el manejo integral de cuencas hidrográficas

Los atractivos culturales más sobresaliente de la ciudad de Calceta y considerados tesoros históricos por sus habitantes son el reloj público, que se instaló el 6 de julio de 1925, adquirido en Italia para la transmisión de la hora, colocado en una torre construida en un edificio que además de soportar el reloj era sede del Museo Arqueológico Histórico "Luis Félix López" y la Biblioteca Municipal. Un resumen de la actualización y jerarquización de los atractivos culturales, así como el grado de afectación provocado por el terremoto, se relaciona en el cuadro 2. 


\begin{tabular}{|l|l|l|l|l|}
\hline No. & NOMBRE DEL RECURSO O ATRACTIVO & CATEGORÍA & AFECTACIÓN & JERARQUÍA \\
\hline 1. & Elaboración de artesanías en barro & Manifestación cultural & Conservado & I \\
\hline 2. & Iglesia Santa Marianita de Jesús & Manifestación cultural & Daños en su estructura & I \\
\hline 3. & Monumento a Simón Bolívar & Manifestación cultural & Conservado & II \\
\hline 4. & Monumento al Balsero & Manifestación cultural & Conservado & II \\
\hline 5. & $\begin{array}{l}\text { Museo Arqueológico Histórico Luis } \\
\text { Félix López }\end{array}$ & Manifestación cultural & Colapso por el terremoto & - \\
\hline 6. & Parque Central Abdón Calderón & Manifestación cultural & Daños en su estructura & II \\
\hline 7. & Parque Ferroviario & Manifestación cultural & Conservado & II \\
\hline 8. & Parque de Membrillo & Manifestación cultural & Conservado & I \\
\hline 9. & Parque de Quiroga & Manifestación cultural & Conservado & I \\
\hline 10. & Plaza Cívica & Manifestación cultural & Daños en su estructura & II \\
\hline 11. & Puente Rojo & Manifestación cultural & Conservado & II \\
\hline 12. & Reloj Público & Manifestación cultural & Colapso & - \\
\hline 13. & Represa Sixto Duran Ballén & Manifestación cultural & Conservado & II \\
\hline 14. & Templo San Agustín & Manifestación cultural & Daños en su estructura & II \\
\hline
\end{tabular}

Cuadro 2. Inventario turístico de recursos culturales del cantón Bolivar

Fuente: Elaborado por los autores

El terremoto provocó afectaciones en numerosos recursos y/o atractivos turísticos culturales del territorio, nombrando algunos como el Templo San Agustín, el Parque Abdón Calderón, con afectaciones considerables, otros atractivos colapsaron como el Reloj Publico, el Museo Arqueológico Histórico "Luis Félix López" y la biblioteca municipal, por lo que el cantón perdió dos de sus más importantes atractivos culturales.

\section{VALORAR LA INFRAESTRUCTURA Y SUPERESTRUCTURA}

Los principales problemas que afronta el Código Orgánico de Organización Territorial, Autonomía y Descentralización (COOTAD), y por ende los procesos de descentralización y entrega de competencias previstos en él según Batallas, (2013) es el desconocimiento en muchos gobiernos autónomos y descentralizados sobre su importancia y alcance, falta de socialización adecuada, así como por el desinterés de las propias autoridades en conocer las nuevas disposiciones legales y más aún las nuevas responsabilidades y competencias dentro de su gestión, cometiendo el error de ver a la descentralización como algo lejano e incluso imposible de implementar en sus circunscripciones territoriales. Asimismo, su poca divulgación atenta contra el principio de participación ciudadana, pues la falta de conocimiento sobre su alcance, y principalmente sobre los procesos que deben vivir los distintos gobiernos, genera precisamente una falta de control y vigilancia por parte de la ciudadanía.

Con el objetivo de evaluar la infraestructura del territorio y poder identificar las relaciones que se establecen entre todos los actores turísticos se realizó una encuesta a los diferentes actores turísticos desde la municipalidad hasta los emprendedores turísticos y la comunidad, se determinó el tamaño de la muestra partiendo de tener un universo infinito y estimándose un margen de error del $6 \%(\mathrm{~d}=0,06)$, la encuesta se centra en evaluar la gestión turística local, se aplica un total de 267 encuestas, las preguntas se dirigen a identificar el nivel de satisfacción con el desarrollo de la actividad turística dentro del territorio y conocer el grado de relación e interacción entre instituciones relacionadas de forma directa e indirecta con el turismo en el cantón Bolívar. Los resultados se muestran en la tabla 2. 


\begin{tabular}{|c|c|c|}
\hline No. & Pregunta & Comportamiento \\
\hline 1. & $\begin{array}{l}\text { ¿Cómo calificas el proceso de levantamiento de problemáticas turísticas por } \\
\text { parte del Departamento de Turismo del cantón? }\end{array}$ & INADECUADO (84\%) \\
\hline 2. & $\begin{array}{l}\text { ¿Su emprendimiento ha recibido la visita del Departamento de Turismo del } \\
\text { cantón con el fin de conocer y evaluar las principales problemáticas que los } \\
\text { afectan? }\end{array}$ & NUNCA (40\%) \\
\hline 3. & $\begin{array}{l}\text { ¿Recibió el asesoramiento adecuado, cuando lo necesito por parte del } \\
\text { Departamento de Turismo del cantón? }\end{array}$ & NO (70\%) \\
\hline 4. & $\begin{array}{l}\text { ¿Consideras adecuada la inversión de recursos económicos por parte del } \\
\text { Departamento de Turismo del cantón, priorizando y atenuando los problemas } \\
\text { más graves, beneficiando a un mayor número de habitantes de la localidad? }\end{array}$ & INADECUADO (72\%) \\
\hline 5. & $\begin{array}{l}\text { ¿Su emprendimiento presenta problemas actuales que pueden ser resueltos } \\
\text { por el Departamento de Turismo del cantón? }\end{array}$ & SI (60 \%) \\
\hline 6. & $\begin{array}{l}\text { ¿Su emprendimiento ha sido beneficiado por la ejecución de proyectos } \\
\text { turísticos municipales? }\end{array}$ & NO (89\%) \\
\hline
\end{tabular}
Tabla 2. Comportamiento de la encuesta a actores turísticos

Fuente: Elaborado por los autores

El análisis de la encuesta a los actores turísticos demuestra que la actividad turística en el cantón Bolívar está estancada, diversas causas y problemáticas propician su comportamiento, existe débil ejecutividad en los procesos para lograr el buen desarrollo turístico, no cuenta con directrices para dirigir sus políticas y cumplir sus objetivos. La multitud de demandas ciudadanas, frente a un presupuesto deficitario y sin planificación, ha hecho que los ciudadanos y ciudadanas pierdan la confianza, lo que hace que pierdan espacios de participación afectando la gestión local.

\section{CARACTERIZACIÓN DE LA OFERTA}

El costo de la reconstrucción de este sector de infraestructura asciende a $862 \mathrm{MM}$ USD, cifra que representa el 25,8\% del monto total de la reconstrucción del país. De este monto, el 89,6 \% corresponde a la reconstrucción de activos, el 7,3\% a costos adicionales y el $3,1 \%$ a flujos perdidos. Asimismo, el 31,2\% de costo corresponde a agua y saneamiento, el $28,3 \%$ a transporte, el $22,7 \%$ a electricidad y el $17,7 \%$ restante a telecomunicaciones (Secretaría General de Riesgos de Ecuador, 2016).

En el caso del cantón Bolívar su territorio está caracterizado por una planta hotelera de pequeños hoteles de capital privado con servicios adecuados para el alojamiento, y con una demanda acertada de clientes que visitan el territorio para el disfrute del turismo rural, sus principales problemas consisten en la no planificación estratégica de la operación hotelera, la ausencia de sistemas de gestión y por ende el déficit en manejar la información y los indicadores estadísticos de explotación y presentar a demás problemas en la calidad del servicio a clientes.

El terremoto no afecto estos centro de alojamiento turístico, sin embrago los centros que ofrecen servicios de restauración si muestran daños en su estructura, se evidenció una alta afectación por su colapsó en los siguientes restaurante: La Olla, Asadero su mejor pollo, Domingo criollo, Doña Meche y a la Asociación de Bares y Restaurantes del mercado central, que disminuyen la oferta en 200 plazas que representa un 53\% de afectación de algún tipo a estos emprendimientos, en la tabla 3, se muestra un resumen estadístico de las afectaciones. 


\section{NO. AFECTACIONES}

CANTIDAD

30

21

45
PORCENTAJE

$31 \%$

$22 \%$

$47 \%$

3. Establecimientos turísticos sin afectación por el terremoto.

Tabla 3. Comportamiento de la encuesta a emprendedores turísticos

Fuente: Elaborado por los autores

\section{IDENTIFICACIÓN DE LA DEMANDA}

El gasto promedio por viaje a Ecuador es de \$1.034 (dólares estadounidenses). La estructura del gasto del turismo receptor se representa en un 35\% alimentación, 19\% alojamiento, $17 \%$ atracciones. $13 \%$ Suvenires y 3\% transporte (MINTUR, 2016). El 58\% viene desde América del Sur, Central y el Caribe y el 16\% viene desde Europa. Alrededor de $67 \%$ de los turistas Ilega por vía aérea y $29 \%$ por vía terrestre. El sector genera uno de cada 20 empleos en el país.

Manabí se destaca por un turismo de sol y playa, sin embrago el cantón Bolívar un territorio al interior se destaca por sus recursos naturales, por lo que conocer iquienes visitan al territorio? y ¿cuáles son sus motivaciones y preferencias? es fundamental para la investigación, se identifica el perfil del visitante a través de una segmentación del mercado, los resultados se muestran en la tabla 4.

\begin{tabular}{|c|c|c|}
\hline & Turismo rural & Turismo familiar \\
\hline Profesión & Empleados en su mayoría & $\begin{array}{l}\text { Cuenta propia en un mayor } \\
\text { porciento }\end{array}$ \\
\hline Nivel de estudios & $\begin{array}{l}\text { El } 55 \% \text { han culminado estudios } \\
\text { Secundarios }\end{array}$ & $\begin{array}{l}\text { Estudios medios (Bachiller) en } \\
\text { mayor porciento }\end{array}$ \\
\hline Veces que ha visitado el cantón & $3-5$ veces $(44 \%)$ & Más de 6 veces (34\%) \\
\hline Tiempo que se queda en el cantón & Pernoctan de 1 - 2 días (69\%) & $\begin{array}{l}\text { El mayor porcentaje hace estancias } \\
\text { de más de } 4 \text { días. }\end{array}$ \\
\hline $\begin{array}{l}\text { Medio por el que se informa sobre lo } \\
\text { que ofrece el cantón }\end{array}$ & Boca a boca $32 \%$, & A través de familiares y amigos \\
\hline Con quienes visita el cantón & Acompañado de amigos $42 \%$ & Acompañado Familia $37 \%$ \\
\hline Tipo de transporte & Propio 56\%, & $\begin{array}{l}\text { La mayoría en Transporte colectivo } \\
\text { (Alquilado) }\end{array}$ \\
\hline Principales motivos de visita & $\begin{array}{l}\text { Disfrutar paisaje y naturaleza } \\
25 \%,\end{array}$ & $\begin{array}{l}\text { Disfrutar de la gastronomía en un } \\
35 \%\end{array}$ \\
\hline $\begin{array}{l}\text { Actividades que le gustaría que se } \\
\text { desarrollen para mejorar su estadía }\end{array}$ & $\begin{array}{l}\text { Nuevos productos turísticos } \\
23 \%,\end{array}$ & $\begin{array}{l}\text { Actividades } \quad \text { culturales } \\
\text { gastronómicas } 38.5 \%\end{array}$ \\
\hline Nivel de satisfacción en su visita & Menos Satisfecho (78\%) & Más satisfecho (93\%) \\
\hline Calidad de la infraestructura & NO (48\%) & No $(28.6 \%)$ \\
\hline Desarrollo de productos turísticos & Bueno (71\%) & Muy Bueno (87\%) \\
\hline
\end{tabular}

Tabla 4. Perfil del visitante

Fuente: Elaborado por los autores utilizándose el SPSS.

Según los resultados estadísticos, se identifican dos clúster, un subgrupo motivado por el turismo rural y el otro por el turismo familiar, ambos grupos difieren en cuanto a sus 
rasgos demográficos en el turismo rural son de profesión empleados y de estudios terminados secundarios en su gran mayoría, sin embargo, en el turismo familiar en un mayor por ciento son trabajadores por cuenta propia y de estudios medios.

Las diferencias más significativas se encontraron en las motivaciones para realizar la visita en un caso disfrutar del paisaje y la naturaleza (rural) para otro disfrutar la gastronomía (familiar), difieren además en las actividades que le gustan, el turismo rural solicita nuevos productos turísticos, y el familiar recomienda más actividades culturales y gastronómicas, también existen diferencias en los integrantes del grupo de viaje en un caso amigos en el otro la familia y en el tiempo de visita siendo superior para el caso del turismo de familia en más de cuatro días.

Con relación a la satisfacción con el destino los que se identifican con el turismo rural muestran una menor satisfacción y hacen una crítica y desfavorable evaluación del territorio en lo relacionado a su infraestructura y desarrollo de productos turísticos. Por otra parte, conviene destacar que ambos grupos representan el 50\% de los encuestados.

\section{IDENTIFICAR LOS PROCESOS DE PLANIFICACIÓN Y ORDENAMIENTO TERRITORIAL DEL GOBIERNO AUTÓNOMO DESCENTRALIZADO}

En la Constitución (2008) vigente del país se señala que la prevención del riesgo, la mitigación de desastres, la recuperación posdesastre y el mejoramiento de las condiciones socioeconómicas son acciones en las que el país debe invertir para proteger de los efectos destructivos de las amenazas naturales a las personas, a las comunidades y sus inversiones, siendo el manejo de los desastres causados por eventos naturales competencia exclusiva del Estado central.

La Constitución define a su vez un Sistema Nacional Descentralizado de Gestión de Riesgos, SNDGR, conformado por el ente rector que es la Secretaría de Gestión de Riesgos, las unidades de gestión de riesgo de todas las entidades públicas y privadas en los ámbitos local, regional y nacional, las entidades de ciencia que estudian las amenazas y vulnerabilidades y otros mecanismos de coordinación como los Comités de Gestión de Riesgos y los Comités operativos de Emergencia (CGR/COE).

Los riesgos en Ecuador se gestionan bajo el principio de descentralización subsidiaria, que implica la responsabilidad directa de las instituciones dentro de su ámbito geográfico. Cuando sus capacidades para la gestión del riesgo son insuficientes, las instancias de mayor ámbito territorial y mayor capacidad técnica y financiera brindan el apoyo necesario con respeto a su autoridad en el territorio, sin relevarla de su responsabilidad.

La Constitución establece que los gobiernos municipales, en el marco de sus competencias deben, entre otras cosas, gestionar los servicios de prevención, protección, socorro y extinción de incendios. Por su parte, el Código Orgánico de Organización Territorial, Autonomía y Descentralización (COOTAD) señala que los municipios son responsables por "la gestión de riesgos que incluye las acciones de prevención, reacción, mitigación, reconstrucción y transferencia, para enfrentar todas las amenazas de origen natural o antrópico que afecten al cantón (la cual) se gestionará de manera concurrente 
y de forma articulada con las políticas y los planes emitidos por el organismo nacional responsable. (Además) los GAD municipales adoptarán obligatoriamente normas técnicas para la prevención y gestión de riesgos sísmicos con el propósito de proteger las personas, colectividades y la naturaleza".

\section{IDENTIFICAR LAS COMPETENCIAS Y FUNCIONES DE LOS ACTORES TURÍSTICOS TERRITORIALES INVOLUCRADOS}

EI MINTUR (2013) establece el Plan estratégico de desarrollo de turismo sostenible para Ecuador con una visión a largo plazo hacia el año 2020 (PLANDETUR 2020), que tiene como finalidad potenciar un desarrollo sostenible integral, además propone la existencia de diferentes niveles de acción que contemplan esquemas de cooperación pública, privada y comunitaria, viables para la gestión de los territorios de desarrollo turístico sostenibles que faciliten la gobernanza.

El Plan Nacional para el Buen Vivir 2013-2017 (SENPLADES, 2013) plantea 12 objetivos y supone enfrentar cuatro grandes desafíos: reforzar la planificación por Objetivos Nacionales para el Buen Vivir; generar procesos de articulación y retroalimentación interestatal que integren la gestión por resultados; incorporar de manera efectiva a la planificación el ordenamiento territorial; e impulsar un proceso de participación social.

Anteriormente abordamos las funciones y competencias del GADs Bolívar, de igual manera es también importante el papel que juega la comunidad en el desarrollo de la actividad turística, todos con iguales posibilidades de participación y al mismo tiempo deben ser los principales beneficiarios del desarrollo del turismo. Su participación e integración ha de estar direccionado a promover interacciones culturales entre sus miembros y los visitantes; seguir activamente las decisiones adoptadas en el desarrollo de nuevos proyectos turísticos; tomar la iniciativa; participar; velar por las normas culturales; preservar y controlar el uso de los atractivos turísticos velando y promoviendo la sostenibilidad; participar y contribuir en los planes de educación dirigidos a elevar la cultura y mejorar la actividad turística.

Identificar las competencias del sector privado también se hace necesario dentro de las que destacan la producción y comercialización de los servicios turísticos, la especialización y diversificación de productos para el cliente; invertir en innovación y en nuevas tecnologías; generar redes o alianzas que permitan el fortalecimiento de sus capacidades competitivas; realizar las adaptaciones y flexibilizarse a los permanentes cambios del mercado; desarrollar la información, la comercialización y el marketing; promover la capacitación de los recursos humanos, fomentar el liderazgo participativo e instrumentar mecanismos de valoración y medición de la calidad de los servicios.

El cumplimiento de competencias y funciones de los actores turísticos territoriales evaluados a través de la aplicación de encuestas y un diagnóstico participativo evidencian que en el territorio la gobernanza turística es deficiente, la gestión turística partiendo del departamento de turismo del GADs Bolívar puede calificarse de deficiente, otras instituciones públicas como la universidad (ESPAM MFL) a través de sus proyectos de investigación y vinculación con la comunidad evidencia un mejor resultado aunque no satisface y las comunidades y el sector turístico del territorio muestran una gestión y cumplimiento de 
sus funciones que pueden calificarse de aceptado, un resumen de este análisis se muestra a continuación en tabla 5.

\section{ANÁLISIS DE LA GOBERNANZA TURÍSTICA}

La planificación de la actividad turística en el cantón Bolívar post terremoto debe enfocarse en el ordenamiento territorial y el desarrollo turístico local, direccionada a la solución de problemas y necesidades de los actores turísticos y en la capacidad de respuesta en correspondencia con los recursos humanos y materiales, se necesita de un proceso de planificación participativo y consensuado, que permita que la comunidad adquiera un compromiso real en cuanto al cumplimiento con lo programado ya que son ellos mismos los que identifican, analizan y proponen soluciones a sus propios problemas.

El desafió que asume el GADs Bolívar para enfrentar el desarrollo local, es promover la participación ciudadana, que se refleja en el involucramiento, la intervención de todos los habitantes en la toma de decisiones, gestión compartida y control social de todos los procesos públicos. Es necesario el fortalecimiento de políticas públicas y la adecuada interacción entre los sectores públicos, privados y la comunidad. Es necesario un reconocimiento mutuo de los actores de los sectores público, privado y comunitario, las organizaciones sociales, los gremios, la academia, empresarios, las ONGs, las asociaciones de consumidores, las empresas y el sector productivo en general, en su pluralidad y diversidad en la legitimidad que tienen todos para tomar parte de las decisiones de planificación y gestión local, permitiendo que la población se convierta en sujeto de su desarrollo y protagonista activo de su transformación.

Es estratégico además una adecuada planificación, asignando los recursos a los problemas más exigidos por los prestadores de servicios turísticos y la comunidad, más aun conociendo la excesiva dependencia del GAD del cantón Bolívar de las trasferencias del estado, caracterizado por un presupuesto muy bajo, por ser un cantón pequeño, además del excesivo gasto operativo, lo que propicia limitados recursos financieros para enfrentar la gestión.

La gobernanza turística del territorio está caracterizada por un sin número de causas que fomentan diversos problemas que han propiciado la deficiente gestión de la actividad turística, dentro de las problemáticas más sobresalientes se encuentran la desorganización de líderes comunitarios y juntas parroquiales por falta de liderazgo, deficiente cumplimiento de las competencias de los actores identificados, y la poca participación ciudadana, escasa información, promoción y comercialización de sus productos turísticos, lo que impide lograr el desarrollo turístico como objetivo común en beneficio de la comunidad.

\section{ANÁLISIS ESTRATÉGICO DE LA SITUACIÓN TURÍSTICA ACTUAL DEL TERRITORIO}

Para el desarrollo de esta actividad se lleva a cabo un análisis situacional que toma en cuenta los elementos internos y externos de un estudio FODA (Fortalezas, Oportunidades, Debilidades y Amenazas) en el ámbito turístico, se identifican los problemas y causas que afectan la actividad turística del territorio. En el cuadro 3, se presentan los resultados. 
Presencia de un Plan de Desarrollo y Ordenamiento Territorial. Diversidad de recursos naturales y culturales de una singular atractividad jerarquizado en categoría II

Existencia de servicio de transporte para movilizarse dentro del cantón.

Recurso hídrico permanente.

Buen estado de conservación y de mantenimiento de sus principales vías de acceso y señalización vial.

Fincas con potencial para agroturismo.

Alto nivel de hospitalidad de los habitantes.

Ofertas variadas de gastronomía tradicional

Emprendedores turísticos con predisposición a mejorar la actividad turística.
Carencia de infraestructura turística de alta categoría.

Desconocimiento del potencial agroturístico.

Ausencia señalización turísticas.

Insuficiencia de servicios básicos.

Alto grado de contaminación a las cuencas y ríos del cantón.

Carencia de organización y planificación de la actividad turística.

Deficiente presupuesto.

Escasa información, promoción y comercialización del turismo.

Inexistente gestión turística integrada entre prestatarios de servicios y el GAD Bolívar.

\section{AMENAZAS}

Situación climática en temporada invernal (inundaciones)

Movimientos sísmicos (replicas).

Inestabilidad económica del GAD Bolívar.

Crisis económica financiera en el país

Fuerte competencia con productos semejantes en cantones cercanos.

Acrecentamiento de la inseguridad social.

Abundantes regulaciones que dificultan emprender en turismo.

Emigración por parte de la población.

Bajo interés en la oferta turística alternativa.

Cuadro 3. Matriz FODA

Fuente: Elaborado por los autores

\section{IDENTIFICACIÓN DE ESTRATEGIAS}

Es necesario facilitar la implementación de las estrategias por parte del departamento de turismo del gobierno autónomo descentralizado del cantón Bolívar, a través de la incorporación de procesos de decisión y gestión para desarrollar el turismo, tomando como base el fortalecimiento de políticas públicas y la adecuada interacción entre los sectores públicos y privados (GADs, instituciones educativas, empresas locales y asociaciones).

Los resultados del posicionamiento estratégico, demuestra que se deben adoptar y/o aplicar estrategias de reorientación, que permitan minimizar debilidades como la inexistente gestión turística integrada entre prestatarios de servicios y el GADs del cantón Bolívar así como el alto grado de contaminación a las cuencas y ríos del cantón que afectan sus atractivos turísticos naturales, y aprovechar oportunidades como la tendencia creciente de los segmentos de turismo de naturaleza, aventura y ecoturismo y el apoyo que brinda el estado ecuatoriano a los emprendedores turísticos con medidas encaminadas a reactivar el turismo, a través de instituciones de financiamiento públicas como el BanEcuador, Corporación Financiera Nacional, entre otras; las estrategias establecidas contribuirán a la mejora de la gestión turística en el territorio, las mismas son presentadas a continuación: 
Estrategias:

1. Restablecimiento de la infraestructura identificándose las zonas más afectadas por el terremoto del 16 de abril.

2. Establecimiento de un sistema adecuado de gobernanza turística mediante el fortalecimiento institucional, la coordinación interinstitucional pública, privada y comunitaria.

3. Diseño de programas de sensibilización y concienciación de la ciudadanía respecto de sus responsabilidades en el cuidado y la conservación del patrimonio natural y cultural.

4. Fortalecer la promoción, comercialización y mercadeo turístico de cantón.

5. Gestionar recursos extraordinarios ante instituciones financieras nacionales e internacionales no reembolsable, que permitan viabilizar las estrategias identificadas.

Las estrategias se direccionan a la solución de la deficiente cobertura de los servicios básicos, complementarios, accesos, sensibilización turística/ ambiental e implementación de facilidades en cada de uno de los sitios donde se desarrollan las actividades turísticas, planificando una adecuada inversión pública en el sector turístico.

\section{CONSIDERACIONES FINALES}

El diagnóstico turístico situacional nos presentó un estancamiento en la gestión turística del cantón Bolívar, agravada por el terremoto del pasado 16 de abril de 2016, se evidencia daños en el sistema turístico, en sus atractivos turísticos, en los establecimientos de alojamiento, gastronomía y actividades turísticas, crece la actividad turística informal, escasa información, promoción y comercialización.

La recuperación y reconstrucción de las zonas afectadas debe tener en cuenta elementos críticos para evitar el restablecimiento de las vulnerabilidades que se evidenciaron luego del terremoto del 16 de abril pasado. Entre ellas se destacan un rápido proceso de urbanización con limitadas capacidades de los municipios para supervisar y asegurar una construcción segura, lo que se refleja en altos porcentajes de construcción informal e ilegal; la informalidad en las prácticas constructivas, el uso de tipologías estructurales inapropiadas para zonas sísmicas, una débil regulación, control y supervisión de la industria de la construcción; la debilidad en el ejercicio de la rectoría en el uso y ocupación del suelo, expresada en el campo regulatorio, y la ausencia generalizada de una conciencia pública de lo sísmico, que no favorece la adopción de políticas y estrategias para hacer frente al riesgo.

Los principales daños en el patrimonio inmueble de la provincia de Manabí se encuentran mayoritariamente en los cantones de Portoviejo, Jama, Sucre, Bolívar y Rocafuerte. Estos daños incluyen: el desplome de elementos (decorativos, ornamentales, terminaciones, acabados, cielos falsos) y daños en tabiques secundarios o mamposterías, dependiendo del sistema constructivo del inmueble. De los 243 inmuebles patrimoniales que sufrieron daños en la Provincia de Manabí, 189 tenían uso de vivienda y 54 uso comercial. También se evaluaron los daños en 4 iglesias patrimoniales. 
En cuanto al fortalecimiento de emprendimientos culturales para la reactivación socioeconómica de la zona, se recomienda la elaboración de una política y un plan de recuperación de festividades, usos sociales, rituales y actos festivos en el territorio, se deberá contemplar un programa de participación y fortalecimiento de capacidades locales para la innovación artesanal y un mapeo de actores e industrias culturales en la zona.

Según los resultados del estudio de la demanda al cantón Bolívar se identifican dos tipos de turismo, uno motivado por el turismo rural y el otro por el turismo familiar, las diferencias más significativamente se encontraron en las motivaciones para realizar la visita, actividades que prefieren, personas que integran el grupo y tiempo de visita, en la relación con la satisfacción con el destino, los que se identifican con el turismo rural muestran una peor satisfacción y hacen una desfavorable evaluación del territorio en lo relacionado a su infraestructura y desarrollo de productos turísticos.

El territorio debe procurar la reactivación de la demanda, mediante políticas de promoción comercial, mejorándose las capacidades del subsector capacitando a los actores, potenciando el nivel de asociación y conformando paquetes turísticos a precios competitivos. Como medidas de reactivación inmediata, se deben desarrollar acciones para promover la demanda a través del turismo solidario, buscándose incentivar la afluencia turística a las zonas afectadas para potenciar su reactivación económica.

Para fortalecer el turismo rural, se recomienda considerar la promoción de la construcción de viviendas con diseños arquitectónicos apropiados para la producción de bienes y servicios, poniendo especial atención en viviendas vinculadas al turismo, por ser esta una actividad importante en términos de medios de vida. Se deben considerar alternativas de financiamiento con condiciones ventajosas, especialmente para pequeños establecimientos que fueron los que sufrieron las mayores afectaciones.

La metodología propuesta permitió la identificación de cinco estrategias dirigidas a la reactivación turística del cantón Bolívar, las mismas se centran en el restablecimiento de la infraestructura en las zonas pobladas de mayor afectación; establecimiento de un sistema adecuado de gobernanza turística; diseño de programas de sensibilización y concienciación de la ciudadanía respecto de sus responsabilidades en el cuidado y la conservación del patrimonio natural y cultural; fortalecer la promoción, comercialización y mercadeo turístico y; gestionar recursos extraordinarios ante instituciones financieras nacionales e internacionales no reembolsable, que permitan viabilizar las estrategias identificadas.

\section{REFERENCIAS BIBLIOGRÁFICAS}

Asamblea Nacional (2010) Código Orgánico de Organización Territorial, Autonomía y Descentralización. Ministerio de Coordinación de La Política Y Gobiernos Autónomos Descentralizados, 81. Retrieved from http://www.ame.gob.ec/ame/pdf/cootad_2012.pdf

Batallas, H. (2013) El actual modelo de descentralización en el Ecuador: un desafío para los gobiernos autónomos descentralizados. Revista de Derecho UASB, 20(18). Retrieved from http://repositorio. uasb.edu.ec/bitstream/10644/4225/1/03-TC-Batallas.pdf

Cabral, M. M. (2016) Estudio sobre el turismo espacio rural en Barra do Piraí y su relación con el desarrollo. Revista Turismo - Visão e Ação, 18(2), 223-250. 
Carvalho, K. D. \& Sócrates, M. G. (2011) EL TURISMO EN LA DINÁMICA TERRITORIAL ¿Lógica global, desarrollo local? Estudios Y Perspectivas En Turismo, 20, 441-461.

Cevallos, F. (2015) Territorialidad: La Gestión del Territorio en el manejo del recurso turístico: Aportes para un Modelo de Gestión basado en experiencias. Revista Turismo Y Desarrollo Local, $8(19)$.

Comité para Reconstrucción y Reactivación Productiva (2016) Plan Reconstruyo Ecuador. Informe trimestral de gestión (mayo-agosto de 2016). (En línea). Documento recuperado en: https://www. reconstruyoecuador.gob.ec/wp-content/uploads/downloads/2016/10/Informe-Asamblea_SeTecReconstrucci\%C3\%B3n_20160830.pdf [Consultado el 15 de enero del 2017].

Constitución de la República de Ecuador (2008) República de Ecuador. Aprobada por la Asamblea Nacional Constituyente. (Documento oficial). Consultado 10 de junio. 2016. Disponible en: http:// ecuadorforestal.org/wpcontent/uploads/2010/05/CONSTITUCION_DE_LA_REPUBLICA_DEL_ ECUADOR_20081.pdf

Domareski, T. C. \& Gândara, J. M., \& Chim, A. F. (2015) Los destinos turísticos como territorios de innovación: análisis de los vectores de competitividad urbana a la luz de los presupuestos sugeridos por la Unión Europea a través del informe "State of European Cities". Revista Turismo - Visão e Ação, 17(3), 758-784.

Fontenele, A. \& Lopes, J. L., (2015) Turismo y sostenibilidad ambiental de la comunidad de Barra Grande, Cajueiro da Praia, Piauí (PI). Revista Brasileira de Pesquisa em Turismo 9(3), 519-536.

Funes, A., Romero, I., \& Espín, E. (2015) El turismo comunitario como estrategia de desarrollo en base al Sumak Kausay en Ecuador. Revista Turismo Y Desarrollo Local, 8(19), 1-15.

Furtado da Silva, L. \& Mantovaneli, O. (2012) Gobernanza y territorialidad en el desarrollo turístico regional. El caso del Oktoberfest en Blumenau - Brasil. Estudios Y Perspectivas En Turismo, 21, 1369-1388.

Garcia, N. \& Doumet, Y. (2017) Producto turístico comunitario para diversificar las economías locales del cantón Bolívar, Ecuador. Revista Interamericana de Ambiente y Turismo - RIAT 13(1), 105-116.

Garcia, N., Carreño, A., \& Doumet, N. (2016) Estrategias para el desarrollo turístico del cantón Bolívar post terremoto del 16 de abril (Ecuador). Revista ECA Sinergia 7(2), 1-25.

Gobierno Autónomo y Descentralizado GAD del cantón Bolívar (2016) Plan de Desarrollo y Ordenamiento Territorial del cantón Bolívar. Ecuador

González, E. A. \& Conde, E. M. (2011) Procedimiento para medir la demanda turística en un destino. Revista de Investigación En Turismo Y Desarrollo Local, 4(11), 1-25.

Instituto Nacional de Estadísticas y Censos INEC (2010) Resultados del censo 2010. Documento recuperado en http://www.ecuadorencifras.gob.ec/censo-de-poblacion-y-vivienda/ [Consultado el 15 de enero del 2016].

Ministerio de Turismo (2007) Plan estratégico de desarrollo de turismo sostenible para Ecuador (PLANDETUR 2020). Quito. Ecuador. Documento recuperado en: http://www.turismo.gob.ec/wpcontent/uploads/downloads/2013/02/PLANDETUR-2020.pdf [Consultado el 15 de enero del 2016]. 
Ministerio de Turismo (2016) Informe de rendición de cuentas 2016. Dirección de Seguimiento de Planes, Programas y Proyectos. Ecuador. Documento recuperado en: https://www.turismo. gob.ec/wp-content/uploads/2017/06/Informe-de-Rendici\%C3\%B3n-de-Cuentas-MINTUR-.pdf [Consultado el 15 de febrero del 2017].

Moscoso, F. V. (2013) El papel de los actores territoriales en la definición y configuración de modelos de desarrollo turístico. Instituto de Investigaciones En Turismo, 1-18.

Perelló, J. L. (2015) Turismo y desarrollo territorial en el Modelo Económico y Social de Cuba. Revista Turismo Y Desarrollo Local, 8(18).

Reyes, M., Manjarrez, N., \& Ortega, Á. (2014). La gestión del turismo comunitario en el marco de la economía popular y solidaria en Ecuador. Revista Turismo Y Desarrollo Local, 7(17), 1-14.

Ricaurte, C. (2009). Manual para el diagnóstico turístico local. Guía para planificadores. Ecuador. (En línea). Documento recuperado en: http://www.aptae.pe/archivos_up/0102-manual-para-eldiagnostico-del-turismo-local-carla-ricaurte.pdf [Consultado el 20 de enero del 2017].

Scarpeta, M. \& Sidnei, R. (2017) Los resultados de las políticas públicas de ecoturismo en áreas protegidas en Brasil y Canadá. Revista Brasileira Pesquisa em Turismo. 11(3), 454-479.

Secretaría General de Riesgos de Ecuador (2016) Informes de Situación No. 65 - 16/05/2016: Terremoto 7.8 Pedernales (16/04/2016) / Réplicas Esmeraldas (18/05/2016). Disponible en: https://www.gestionderiesgos.gob.ec/wp-content/uploads/downloads/2016/05/Informe-desituaci\%C3\%B3n-n\%C2\%B065-especial-16-05-20161.pdf. Consultado el 20 de mayo de 2017.

SENPLADES (2013) Plan Nacional de Desarrollo, Plan Nacional para el Buen Vivir 2013-2017, Quito, Ecuador. (En línea). Documento recuperado en: http://www.buenvivir.gob.ec/versionesplan-nacional [Consultado el 15 de enero del 2016].

SENPLADES (2016) Evaluación de los costos de Reconstrucción. Sismo en Ecuador - abril 2019. Resumen Ejecutivo. Ecuador. (En línea). Documento recuperado en: http://www.planificacion.gob. ec/wp-content/plugins/download-monitor/download.php?id=9028\&force=0 [Consultado el 15 de febrero del 2017].

Tomás Carpi, J. A. (2008). El desarrollo local sostenible en clave estratégica. Revista de Economía Pública, Social Y Cooperativa, 61, 73-101.

Toselli, C. \& Mazza, C (2014) Planes Estratégicos de Turismo para el Desarrollo Local. Una Propuesta de análisis a partir del Método de los "Interrogantes Fundamentales." Revista de Investigaciones Turísticas, 9, 45-68.

Velasco, M. (2016). Entre el poder y la racionalidad: gobierno del turismo, política turística, planificación turística y gestión pública del turismo. Pasos, 14, 577-594.

Wallingre, N. (2014). Turismo, territorio y municipio. Revista de La Facultad de Ciencias Económicas Y Sociales. FACES. Universidad Nacional de Quilmes, 42(43), 143-164. 